\title{
Adenoma Detection Rate in Patients Younger Than 50 Years of Age: Relationship of the Adenoma Detection Rate to Interval Cancer
}

\author{
In Ja Park \\ Department of Colon and Rectal Surgery, Asan Medical Center, University of Ulsan College of Medicine, Seoul, Korea
}

See Article on Page 46-51

The incidence of colorectal cancer in Korea has been increasing rapidly, and worldwide age-standardized rate of colorectal cancer per 100,000 population was the highest in the world in 2012 [1]. Thus, now is the time to make an effort to prevent colorectal cancer nationwide. Colonoscopy is the gold standard for primary or follow-up testing to detect colorectal cancer, and the early detection and removal of a precancerous adenoma by using colonoscopy is well known to reduce the risk of colorectalcancer-related death $[2,3]$. The authors of "Distribution of the Colonoscopic Adenoma Detection Rate According to Age: Is Recommending Colonoscopy Screening for Koreans Over the Age of 50 Safe?" cautiously suggest an earlier first-time colonoscopy based on the higher adenoma detection rate for males in their 40's [4].

An inverse relation between the adenoma detection rate (ADR) and the risk of interval cancer has been shown in largescale studies [5, 6]. Corley et al. [6] compared interval cancer risks among ADRs. According to their report, for patients with an ADR higher than $33.5 \%$, as compared with patients with an ADR lower than $19.05 \%$, the risk of receiving a diagnosis of fatal interval colorectal cancer was reduced by $62 \%$. In their report, each $1 \%$ increase in the ADR was associated with a $5 \%$ decrease in the risk of a fatal interval colorectal cancer. Therefore, an ADR rate higher than $30 \%$ needs to be the focus in terms of pre-

Correspondence to: In Ja Park, M.D.

Department of Colon and Rectal Surgery, Asan Medical Center, University of Ulsan College of Medicine, 88 Olympic-ro 43-gil, Songpa-gu, Seoul 138-736, Korea

Tel: +82-2-3010-3937, Fax: +82-2-474-6701

E-mail: ipark@amc.seoul.kr

(C) 2015 The Korean Society of Coloproctology

This is an open-access article distributed under the terms of the Creative Commons Attribution NonCommercial License (http://creativecommons.org/licenses/by-nc/3.0) which permits unrestricted noncommercial use, distribution, and reproduction in any medium, provided the original work is properly cited. venting fatal interval cancer.

Adenoma detection by colonoscopy depends on various factors concerning the patient, the endoscopist, and the procedure. Bae et al. [4] showed an overall detection rate of $35.4 \%$, which is similar to or a little bit higher than the values published in other reports in Korea $[7,8]$. The reason for the higher ADR is not clear. The higher ADR might be due to an actual increase in adenoma occurrence because colonoscopy is now being performed more and physicians have become more experienced. In that report, the ADR of males in their 40's is noteworthy. It is similar to the overall ADR for patients in their 50's. Therefore, the authors' suggestion appears reasonable, especially in circumstances where the rate of young-age colorectal cancer (age lower than 50 years) is increasing [9]. However, before any discussion of early first-time colonoscopy, whether or not this high ADR rate in younger patients is an institution-specific finding needs to be considered. The ADR by age needs to be determined based on a large-scale database review or a prospective evaluation, with patient- and physician-specific factors considered.

\section{CONFLICT OF INTEREST}

No potential conflict of interest relevant to this article was reported.

\section{REFERENCES}

1. National Cancer Center. Annual report of cancer statistics in Korea in 2012 [Internet]. Goyang: National Cancer Center; c2015 [cited 2015 Apr 13]. Available from: http://ncc.re.kr/manage/ manage03_033_list.jsp.

2. Zauber AG, Winawer SJ, O'Brien MJ, Lansdorp-Vogelaar I, van Ballegooijen M, Hankey BF, et al. Colonoscopic polypectomy and long-term prevention of colorectal-cancer deaths. N Engl J Med 2012;366:687-96.

3. Brenner H, Chang-Claude J, Seiler CM, Rickert A, Hoffmeister M. Protection from colorectal cancer after colonoscopy: a popula- 
tion-based, case-control study. Ann Intern Med 2011;154:22-30.

4. Bae T, Ha Y, Kim C, Lee J, Ha K, Shin S, et al. Distribution of the colonoscopic adenoma detection rate according to age: is recommending colonoscopy screening for Koreans over the age of 50 safe? Ann Coloproctol 2015;31:46-51.

5. Rogal SS, Pinsky PF, Schoen RE. Relationship between detection of adenomas by flexible sigmoidoscopy and interval distal colorectal cancer. Clin Gastroenterol Hepatol 2013;11:73-8.

6. Corley DA, Jensen CD, Marks AR, Zhao WK, Lee JK, Doubeni $\mathrm{CA}$, et al. Adenoma detection rate and risk of colorectal cancer and death. N Engl J Med 2014;370:1298-306.

7. Park HW, Byeon JS, Yang SK, Kim HS, Kim WH, Kim TI, et al. Colorectal neoplasm in asymptomatic average-risk Koreans: the
KASID prospective multicenter colonoscopy survey. Gut Liver 2009;3:35-40.

8. Kim JK, Choi YS, Suh JP, Lee IT, Youk EG, Lee DS. Results of screening colonoscopy in asymptomatic average-risk Koreans at a community-based secondary hospital. Korean J Gastrointest Endosc 2010;41:266-72.

9. U.S. Department of Health and Human Services, National Institutes of Health, National Cancer Institute, Surveillance, Epidemiology, and End Results (SEER) Program. SEER Stat Fact Sheets: Colon and Rectum Cancer [Internet]. Bethesda (MD): National Cancer Institute; c2015 [cited 2015 Apr 13]. Available from: http://seer.cancer.gov/statfacts/html/colorect.html. 